\title{
Socio-demographic Characteristics of School Dropouts in Mahbubnagar District of Telangana State, India
}

\author{
Deepak Kumar Dey*
}

\section{Abstract:}

Free and compulsory education to all children up to the age of fourteen years is the commitment of the Constitution of India. The governments of India and state governments have initiated a number of programmes to achieve the goal of universalization of elementary education. Among them Sarva Shiksha Abhiyan (SSA) is the recent addition. According to the handbook of education statistics (2013-14), 38.2 per cent of children in the state who had enrolled in Class I did not reach Class X and were thus, deprived of basic education. To improve retention in government schools, understanding the socio-demographic characteristics of the parents of school dropout children would be advantageous. For the purposes of the study, a field survey was conducted in 18 villages of six rural Mandals of Mahbubnagar district with a sample of 401 respondents. Study finding revealed that both boys and girls in the age group of six to 18 years were equally vulnerable to dropouts. About 90 per cent of the school dropout children were from the government schools and three in five children in the age group of 15 to 18 years were dropped out from the school.

* PhD Scholar, Jodhpur National University, Rajasthan, India; dkdey@unicef.org 
Keywords: Education, Socio-economic, Dropouts, Retention, Social Protection

\section{Introduction and context setting}

Education is an important vehicle for holistic growth of individual and systematic expansion of an intellectual society. Even after 69 years of country planning, enormous funding and promises, total literacy remains to be a distant dream. Several initiatives for encouraging children for education by the union and state government have resulted in improvements in the overall gross and net enrolment. However, completion of high school education is still puzzling to all.

Continuous rejection of school by the dropped out children had led to waste of public resources in terms of time, money and person day and opportunity cost to the society. School dropout is the manifestation of dysfunctional education system and social disorganisation. Among many factors, low parental attitude towards learning, their educational level, un-successful migration, family income level, interest of children, delinquent behaviour, and unfavourable peer group influence the academic achievement of students.

The state government provides schooling facility to school-aged population, which stands at 61.78 lakh children. During 2014-15, there were 43,208 schools of various managements functioning in the state. The District Information System for Education (DISE) data for 2013-14 academic year collected across 10 districts of Telangana presents a pathetic situation of primary education in the state of Telangana. Mahbubnagar district tops the chart (53.2 per cent) of school dropout rate in Telangana. 38.2 per cent of children in the state have been enrolled in class I but have not reached Class $\mathrm{X}$, thereby remained deprived of basic education. 


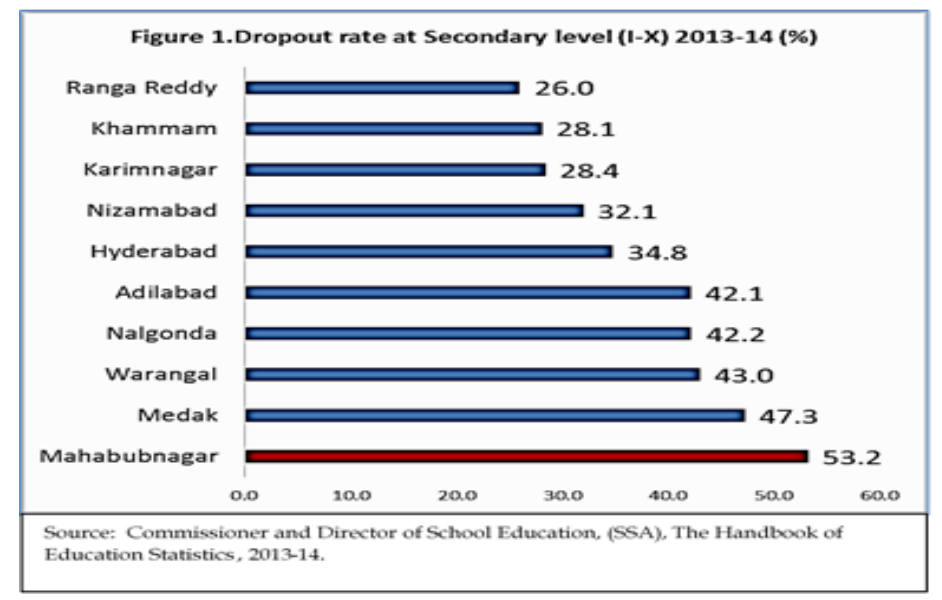

Fig1

As most of the children studying in government schools belong to low socio-economic status, therefore, the present article has policy relevance more in the context of providing free and compulsory education from Kinder-Garten (KG) to Post graduation (PG) in the newly created Telangana state. The researcher has also gathered that most of the evidences on dropouts are providing generic reasons irrespective of geographical, gender and social settings that affect the children in different ways.

Keeping this in mind, the researcher has attempted to review the socio-demographic characteristics of schools dropout families and describe the characteristics of these children. This article would be of particular interest for the newly created state Telangana.

It is expected that this article will provide evidences to stakeholder(s) who are engaged in education to draw innovative strategies for supporting low socio economic status families to retain their children in school and improve their capabilities to take interest in education of their children. The researcher has looked into key characteristics of dropout families like age of the children, housing structure, migration pattern, family support system, annual income, delinquent behaviour of child, education status of parents, social protection benefits. This will help them to predict dropouts in advance. 


\section{Brief Profile of Mahbubnagar District}

The state of Telangana, in southern India, is divided into 10 districts. Mahbubnagar is the largest district by area. According to Census 2011, the district is predominantly rural with a total population of 4.05 million. It had 0.7 million Scheduled Caste (17.5 per cent) and 0.36 million Scheduled Tribe (nine per cent) of the total population. The basic indicators of Mahbubnagar district revealed that it is one of the lowest per capita income districts in the state of Telangana. It is also lagging behind all other districts of the state in all the three indicators of human development i.e. education, health and standard of living; even though the literacy rate improved over the years, it still has the lowest female literacy rate of 45 per cent (Census 2011). As per National Sample Survey, 68 $8_{\text {th }}$ Round, the Net Enrolment Rate for rural boys was 75 per cent and rural girls was 76 per cent whereas urban boys was 93 per cent and urban girls was 94 per cent in the district. The current rural area's attendance rate among 6-18 year old boys and girls was 82 per cent and 80 per cent respectively whereas for urban areas, it was 97 per cent and 95 per cent for the boys and girls respectively in this district.

The data for 2013-14 academic year, collected across the districts of Telangana State by the Commissioner and Director of School Education, SSA, presents the highest rate of dropouts in Mahbubnagar District (53.2 per cent).

The data shows clear disparity between rural and urban areas. Looking at the disparity and disadvantage situation in rural areas, the study was primarily focused in the rural areas of Mahbubnagar district.

\section{Objectives of the study}

The study aims to examine socio-demographic characteristics of school dropouts in rural Mandals of Mahabubnagar district of Telangana state.

\section{Study Methodology}

Mandal-wise dropout data of 6-18 years age group of children for the year 2013-14 was provided by the education department of Telangana state. 
The researcher has also refer rural Mandal-wise details of 2011 census population to calculate dropout rate of children in the age group 6-18 years as a percentage of population in the age group 7+ years. The sample selection is at three stages i.e. selection of mandals in Mahbubnagar district; selection of villages within the selected mandals and selection of all households where the children aged 6 to 18 years dropped out of school. The sample mandals and villages were selected using circular systematic random sampling technique.

\section{Findings from the field survey}

This section presents the household survey results of the field study carried out in six rural Mandals.

\section{Dropout children by social category and gender}

Table 1 indicates that among all social categories from the household listing data, the highest proportion of children (60 per cent) were from Backward Caste (BC) and the lowest proportion of children was from Scheduled Tribe (ST). Overall, one out of ten children were dropouts from the schools in the sample villages. It was also revealed that maximum proportions of school dropouts were from Schedule Tribes and Schedule Caste subsequently. The proportions of school dropouts are equal among boys and girls.

Table 1: School dropout children by social category and gender

\begin{tabular}{|l|c|c|c|c|c|c|}
\hline & \multicolumn{2}{|c|}{ All Children (\%) } & \multicolumn{2}{c|}{ Boys (\%) } & \multicolumn{2}{c|}{ Girls (\%) } \\
\hline $\begin{array}{l}\text { Social } \\
\text { Categories }\end{array}$ & Total & Dropouts & Total & Dropouts & Total & Dropouts \\
\hline $\begin{array}{l}\text { Schedule } \\
\text { Caste (SC) }\end{array}$ & 26 & 12 & 25 & 11 & 26 & 12 \\
\hline $\begin{array}{l}\text { Schedule } \\
\text { Tribes (ST) }\end{array}$ & 5 & 17 & 5 & 17 & 6 & 18 \\
\hline $\begin{array}{l}\text { Backward } \\
\text { Caste (BC) }\end{array}$ & 60 & 7 & 61 & 8 & 58 & 7 \\
\hline $\begin{array}{l}\text { Other } \\
\text { Castes } \\
\text { (OC) }\end{array}$ & 10 & 6 & 9 & 5 & 10 & 6 \\
\hline All & 100 & 10 & 100 & 10 & 100 & 10 \\
\hline
\end{tabular}




\section{Magnitude of school dropped by age and gender}

Among 401 school dropout children, about 45 per cent were girls and 55 per cent were boys respectively. The Table 2 shows that the highest (65 per cent) dropouts were in 15-18 years age group and lowest (seven per cent) were in age group of 6-10 years.

Table 2 : Age wise distribution of school dropouts

\begin{tabular}{|c|l|c|c|c|c|}
\hline \multirow{2}{*}{ Sl. No. } & \multirow{2}{*}{$\begin{array}{c}\text { Age Groups } \\
\text { (in years) }\end{array}$} & \multirow{2}{*}{$\begin{array}{c}\text { All } \\
\text { Children }\end{array}$} & \multirow{2}{*}{ Dropouts } & \multicolumn{2}{|c|}{$\begin{array}{c}\text { Gender Wise } \\
\text { Dropouts }\end{array}$} \\
\cline { 5 - 6 } & & & $7 \%$ & $56 \%$ & $44 \%$ \\
\hline 1 & $6-10$ & $41 \%$ & $38 \%$ & $45 \%$ & $55 \%$ \\
\hline 2 & $11-14$ & $33 \%$ & $28 \%$ & $59 \%$ & $41 \%$ \\
\hline 3 & $15-18$ & $26 \%$ & $65 \%$ & $59 \%$ & $45 \%$ \\
\hline 4 & Total & $100 \%$ & $100 \%$ & $55 \%$ & Goys \\
\hline
\end{tabular}

It was also evident from Table 2 that proportions of school dropouts for boys and girls were almost equal in all the age intervals.

Among the total dropouts within each age groups, proportions of girls are maximum in 11-14 years where as proportions of boys are maximum in the age groups of 6-10 years and 15-18 years.

\section{Discontinuation}

- About 94 per cent of the dropout children in the age group 6 to18 years are from government schools. Children who never went to school is 12 per cent. However, it is a matter of concern that majority of these former children belonged to ST category. Following are the key facts that are revealed from the analysis of primary data On an a average, a child's regularity gets interrupted about 1.2 times a year due to health and work related reasons in all caste groups except General.

- An average child's studies get interrupted for 23 days and it is the highest (33 day) among BC.

- Average age of a child's enrollment in Class-I is 5.2 years, which is almost the same across all socio-economic classes. 
- The average age at which a child dropout from the school is 12 years.

\section{Locations of school dropouts}

The school dropout rates were highest in Utkoor and Mahbubnagar of the six sample rural Mandals. The dropout rates were especially high in the age group of 11 to 14 years implying that children were either not completing secondary level schooling or not pursuing higher secondary level schooling.

All the three sampled villages in Utkoor Mandal have primary schools within close vicinity while higher education institutions are outside. Children had to walk around 2 kilometers along with a bus ride for secondary schooling and above. In Mahbubnagar Mandal, one village has primary school, but there was no proper road to reach the village. The other two villages had schools up to higher secondary within the village as they are located close to Mandal headquarters which has all educational institutions.

In Utkoor and Nawabpet Mandals, one-third of the children in the age group of 15 to 18 years are school dropouts. In dissection, it was as high as 59 per cent among SC children in Utkoor Mandal and 50 per cent for OC children in Nawabpet Mandal. Meanwhile, in Pangal Mandal, a little over one tenth of children are dropouts with two third children being from ST category. In Nawabpet Mandal, all four sampled villages report availability of primary school in the village. For further education, children have to walk or travel a minimum of three kilometres.

One village in Pangal Mandal even boasts of being an educational hub with several educational institutions up to college level attracting students from neighbouring villages for higher studies.

\section{Family demography}

The finding indicates that households with at least one member educated above secondary level had negligible out-of-school (dropout or never enrolled) children irrespective of the age group.

The most susceptible factors which increases the risk of dropping out from school include being a ST or SC child, parents with poor educational background, being a girl and transition of schooling 
stage from lower to higher level (upper primary to higher secondary level).

- The average household size was five with household size being six among OC and ST categories.

- The average sex ratio was 921, in ST category it was significantly low at 762 and quite high in SC category at 1008. The lowest quintile had the sex ratio of 1110 .

- Considering social categories, more than half of the dropout children belonged to BC category; one-third belonged to SC category; nine and five per cent belonged to ST and OC category respectively.

\section{Parental education and their occupation level}

Majority of the drop out children had illiterate parents. About 94 per cent of mothers and 82 per cent of fathers of dropout children were illiterate. In general, illiteracy amongst parents was more in SC, ST and BC categories.

Parents of dropout children mostly work as agricultural and nonagricultural labourers. About 61 per cent fathers and 68.5 per cent mothers works as daily labourers. A large majority of these workers belonged to SC and ST categories. The corresponding data for SC category was 76 per cent for males and 87 per cent for females. Similarly for ST category, it was 61 per cent for males and 74 per cent for females.

\section{Social protection mechanisms accessed by the families}

Being a welfare state, in India, social protection coverages are provided by government. Both central government and the state government provided several social protection mechanisms to support the marginal and vulnerable population. A majority of the households had access to these coverages.

The average annual consolidated gross income of dropout family was Rupees 96,477 (Standard Deviation is INR 66,781) and median value was Rupees 78,000 only. Approximately, 52 per cent households were living in Kutcha iand Semi Puccaii houses. About 90 per cent households were holding below poverty line cards. About 80 per cent households were part of self-help groups. 
The food supply through the Public Distribution System (PDS) is one of the most prominent indirect service delivery. About 96 per cent of the dropout child households had accessed PDS. It was found that social transfers for labour projects reduces risks and associated vulnerabilities.

The present study revealed that

- About 68 per cent of the households access MGNREGA with $\mathrm{BC}$ households leading with highest involvement at 72 per cent.

- Households also receive benefits to a lesser extent from drinking water scheme (34.6 per cent), pension ( 36 per cent), health related schemes (15.8 per cent), sanitation scheme (8.4 per cent) and skill improvement (2.5 per cent).

- Approximately, 50 per cent reported children getting/accessing mid-day meals provided at school and 55 per cent households reported receiving one or other benefits from the school.

\section{Migration in the Families of Dropout Children}

Migration is a risk mitigation strategy for the families. It may be due to push or pull factors - distress at source or search for better opportunities at destination.

Nevertheless, migration is a major factor for drop outs as the parents take the children along with them leading to discontinuation of children's schooling. Whether the household migrated as a whole or partly or individually, children are always affected.

At the destination, children drop out due to difference in language or inaccessible educational facilities, and eventually their poor economic situation forces them to work. When children were left behind at source locations, the relatives/caregivers were least concerned about their education. 
Table 3 : Percentage of households reporting migration

\begin{tabular}{|l|l|l|l|l|l|}
\hline Description of Variable/Caste & SC & ST & BC & OC & All \\
\hline Per cent of households reporting migration & 26 & 36 & 25 & 20 & 26 \\
\hline $\begin{array}{l}\text { Migration with wife or husbands without } \\
\text { children }\end{array}$ & 20 & 15 & 15 & 0 & 16 \\
\hline Migration of Wife/Husband with all children & 20 & 31 & 19 & 25 & 21 \\
\hline Wife /Husband along with a few children & 23 & 23 & 11 & 0 & 16 \\
\hline
\end{tabular}

About 26 per cent of the households reported migrating for more than two or more months at a stretch in the previous year with highest among ST categories (36 per cent). Approximately, 21 per cent households migrated as a family, 16 per cent households migrated with few children leaving others at village and 16 per cent by single parent alone. About 46 per cent households left their children in the source villages at the care of grandparents or relatives.

\section{Social work interventions to prevent school dropouts:}

The researcher is suggesting five-pronged efforts to address school dropouts:

I. Promote child friendly schools and improve learnings- By conducting periodic public hearings and using the findings to strengthen the RTE act to ensure quality elementary education to all children in a child friendly and child centric environment to ensure learning.

II. Ensure all children in school up to secondary level - Using community mobilization as a vehicle to improve preparedness for schooling depends on how children are getting an early start and readiness in learning at the early childhood centres. Hence, strengthening the early childhood care and education (ECCE) shall support the retention and improved learning of the children.

III. Improve parent-teacher relationships and parent's involvement Strengthening of soft skills of teacher as well as parent's 
involvement mechanisms in the school. This will improve quality interactions.

IV. Empowering community for demanding quality education and to promote equity - Effort to welcome children from diverse and socially vulnerable groups to school and to encourage learning can be more effectively directed at community level. Strengthening School Management Committee (SMC) is absolutely crucial at this juncture.

V. Effective social and behaviour change methods to be used for empowering community to remove and fight against the vile of gender specific inequalities, early marriage, and support system for children of distress migrants, child labour, delinquency behaviour.

VI. Increasing the coverage of broader social protection networks - As observed in the study, any social protection mechanisms provides support/ relief to the children. Through an integrated multi-sectoral approach, well-functioning social protection systems can contribute to addressing many of the underlying causes of increased risk and vulnerabilities.

\section{Conclusion}

The study clearly establishes that the characteristics of households with dropout children do not vary widely. The households earn low incomes mostly on daily basis with very little capacity to meet income shocks. Low education levels and low social status in community ascribed through the social categorisation are other notable characteristics. These findings are consistent with the study results of Kainuwa and Yusuf (2013), which concludes that low socio economic status and low educational background of parents negatively affects children's academic achievements because they both prevent access to vital resources and create additional stress at home.

Looking that the profiles of children and their households' characteristics, it is evident that parents with low education may not be in a position to provide supportive supervision to their wards due to insufficient knowledge and respect towards education. This results in reduced monitoring and involvement in 
educational life of their children resulting in discouragement and eventually dropping out of school of these children.

Therefore, it is important that government concentrates more in strengthening the functioning of the school management committees in letter and spirit; creating awareness among parents and children on the importance of education through NGOs, engaging community level activists, and through publicity; counseling parents and teachers to handle children delicately by not scolding or by physical punishment; and implementing the prevention of child marriages act in true spirit by highlighting the importance of girl child education for the benefit of society and for future generation and most importantly, design, implement and track integrated social protection package for the low socioeconomic status households.

\section{References}

Bachman, J. G. (1972), Dropouts are losers: Says who? Today's Education, $61,27-29$.

Commissioner and Director of School Education (2013-2014), The Handbook of Education Statistics (Telangana 10 Districts), Rajiv Vidhya Mission (SSA), Andhra Pradesh. P 71.

Kainuwa, A. and Yusuf. N.B.M (2013). Influence of Socio-Economic and Educational Background of Parents on their Children's Education in Nigeria. International Journal of Scientific and Research Publications, 3(10).

Lewin, K.M. (2007), Improving Access, Equity and Transitions in Education: Creating a Research Agenda, CREATE Pathways to Access Series, No 1. Brighton: University of Sussex.

Sikdar Satadru and Mukherjee Anit N. (2012). Enrolment and Dropout Rate in School Education. Economic and Political Weekly, 47(1), 2731.

i According to the Census 2011 definition, building is treated as kutcha that has its walls and/or roof of which are predominantly made of material such as unburnt bricks, bamboos, mud, grass, reeds, thatch, plastics / polythene, and loosely packed stone.

ii According to the Census 2011 definition, building is treated as pucca that has its walls made of materials like stones, burnt bricks, cement bricks, concrete and roof material like machine-made tiles, cement tiles, burnt bricks, cement bricks, stones, slate, concrete. 